\section{Juan D. Cid Hidalgo}

Doctor en Literatura Latinoamericana de la Universidad de Concepción. Sus líneas de trabajo se despliegan alrededor de la novela y narrativa chilena e hispanoamericana. Ha participado en varios proyectos de investigación como «Premiar y castigar. La novela de aprendizaje y el poder disciplinario en la literatura hispanoamericana del siglo XIX y XX», «Literatura en seis cuerdas» y «Aljibe de madera. Guitarra y literatura», ambos proyectos interdisciplinarios de Creación Artística del Departamento de Música de la Universidad de Concepción. Actualmente es investigador responsable del proyecto FONDECYT Postdoctoral «Novela, filantropía y saber. Ficcionalizaciones de la locura en Latinoamérica» y coordinador del Área de Investigación «Nuevas lecturas de los textos clásicos de la Literatura Latinoamericana» de la Universidad de Concepción.

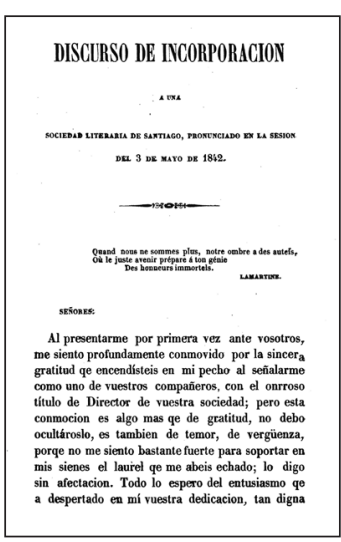

Discurso de incorporación a la Sociedad de Literatura de Santiago.

1

Esta investigación forma parte del proyecto FONDECYT $\mathrm{N}^{\circ}$ 3100007 Novela, filantropía y saber. Ficcionalizaciones de la locura en Latinoamérica.

2

Esta brevísima novela fue publicada en París en 1875, bajo el título de Antaño i Ogaño, título que en 1885 se mantiene pero integra otros relatos: El crepúsculo (1843), El mendigo (1843) El Alférez Alonso Díaz de Guzmán (1848), Rosa (1847), Don Guillermo (1860), Diario de una loca (1875), Mercedes (1875) y Una hija (1881). Para efectos de esta investigación citamos de la versión de Leipzig de 1885.

Filantropía, democracia, locura Diario de una loca de José Victorino Lastarria JUAN D. CID HIDALGO

\title{
FILANTROPÍA, DEMOCRACIA, LOCURA. DIARIO DE UNA LOCA DE JOSÉ VICTORINO LASTARRIA
}

\author{
JUAN D. CID HIDALGO \\ Universidad de Concepción, Chile \\ jdcid@udec.cl
}

\section{RESUMEN}

Tanto en sus escritos narrativos como en los políticos, sociológicos e históricos, es posible percibir en José Victorino Lastarria un idealismo latente -cifrado en la máxima «combatir la ignorancia»-que va construyendo una filantropía señera en las coordenadas latinoamericanas. La relación puente entre este concepto y su tratamiento en Diario de una loca (1885) evidencian cómo esta breve novela proyecta las paradojas constitutivas de una estructura sustentada por el poder estatal que permite la asunción de ciertos rostros alternos, pero que inexorablemente terminan condenados por una lógica punitiva que los borra, o al menos, los reduce por medio de la fuerza, dándole la más humana de las formas justificando médicamente sus razones. De esta manera el texto desenmascara la filantropía falaz que desestima los derechos individuales en pos del orden y seguridad de la mayoría estadística.

Palabras clave: diario, disciplina, filantropía, José Victorino Lastarria, locura, saber, vigilancia.

\section{ABSTRACT}

In his narrative writings, as well as in his political, sociological and historical writings it is possible to percieve a latent idealism of Jose Victorino Lastarria - encoded in the maxim «fight against ignorance» - that is building a unique philanthropy in Latin American coordinates. The relationship between this concept and its treatment in Diario de una loca (1885) proves how this short novel shows constitutive paradoxes of a structure held by the state power that allows the assumption of certain people who take turns, but they inexorably end up condemned by a punitive logic that erase them, or at least, reduce them by means of force, giving it the most human form and justifying medically its reasons. Therefore, the text exposes false philanthropy that rejects individual rights towards order and security coming from statistical majority.

Keywords: diary, discipline, philanthropy, Jose Victorino Lastarria, madness, knowledge, surveillance.

La paradoja que significa igualar locura y ejemplaridad nos ayudará sistemáticamente a pensar esta perturbadora proposición de José Victorino Lastarria sustentada en Diario de una loca $(1875)^{2}$, texto que dista del tono lastarriano a que hemos estado habituados, pero que proyecta deliberada y permanentemente aquello tan propio de una de las mentes 
fundantes del progresismo decimonónico ${ }^{3}$. La destacada investigadora Jean Franco en $\mathrm{La}$ cultura moderna en América Latina (1985) sostiene que «En el siglo XIX la literatura se concibió no sólo como instrumento de protesta social sino también como medio para modelar la conciencia nacional y crear un sentimiento de tradición» (Franco, 1985, p. 15), precisamente de este modo entendemos las intenciones del proyecto lastarriano de levantamiento de un estado nacional moderno que no reproduzca el orden conservador, donde la implementación de una historia social, cultural e ilustrada posibilite la conformación de una historia fundada en la búsqueda de la libertad y el bien común, junto a la posibilidad de oír otras voces y, por tanto, otros actores sociales. De esta manera la literatura cobra un interés inusitado para el político, como lo confirman algunos párrafos de su «Discurso de incorporación a la Sociedad Literaria» (1842):

No, Señores, fuerza es que seamos orijinales; tenemos dentro de nuestra sociedad todos los elementos para serlo, para convertir nuestra literatura en la expresion auténtica de nuestra nacionalidad. $\mathrm{Me}$ preguntareis qué pretendo decir con esto, y os responderé con el atinado escritor que acabo de citaros, que la nacionalidad de una literatura consiste en que tenga una vida propia, en que sea peculiar del pueblo que la posee, conservando fielmente la estampa de su carácter, de ese carácter que reproducirá tanto mejor mientras sea mas popular. Es preciso que la literatura no sea el exclusivo patrimonio de una clase privilejia$d a$, que no se encierre en un circulo estrecho, porque entónces acabará por someterse a un gusto apocado a fuerza de sutilezas. Al contrario debe hacer hablar todos los sentimientos de la naturaleza humana y reflejar todas las afecciones de la multitud, que en definitiva es el mejor juez, no de los procedimientos del arte, si de sus efectos (Lastarria, 1842, p. 14).

Con estas palabras llenas de confianza y fe en las posibilidades del porvenir, Lastarria traduce una preocupación encomiable que tiene relación con el aporte que aquellos desestimados pueden efectuar en la formación de una historia común basada en el diálogo, la tolerancia y el respeto, aunque a poco andar su impracticabilidad quede manifiesta no solo en la brevísima novela de José Victorino Lastarria sino en múltiples episodios nacionales que hemos experimentado fuera de la ficción. En Locura y democracia. Ensa- yos sobre la forma unaria (2002) el pensador francés Dany-Robert Dufour pone en diálogo a Logos y Sogol (lo unario y lo binario), conceptos que en un constante debate han dejado de percibir al Otro como fundamento político de las sociedades modernas ${ }^{4}$. En el texto Dufour señala que durante la génesis de las sociedades democráticas «Antes de la época clásica, el loco era todo menos yo; se refugiaba en su alteridad radical e inalcanzable. En la época clásica fue encerrado, lo que paradójicamente ya es muestra de un modo de actuar frente a él. Justo después de la Revolución francesa, apenas en el comienzo del siglo XIX, se concluyó que el loco no siempre está loco y se utilizó esta distinción para entablar comunicación con él» (Dufour, 2002, p. 116).

Es en este eje de «entablar comunicación» en el que se instala la escritura lastarriana de Diario de una loca. Diálogo que plasma las paradojas constitutivas de una estructura sustentada por el poder estatal que permite la asunción de ciertos rostros alternos, pero que inexorablemente terminan condenados en una dinámica punitiva que los borra, o al menos, los reduce, consumando, sin embargo, uno de sus retos: exhibir su existencia.

«¿Qué anuncia el saber de los locos?», nuevamente la pregunta foucaultiana se nos atraviesa como pretexto para «pensar» de otra manera las relaciones entre locura y saber, contienda que se ha mantenido en tablas durante mucho más tiempo que el razonable, no obstante, la influencia productiva y recíproca de ambos términos. Logos y Sogol, entonces, en plática y debate continuo abren una línea de acceso a la comprensión de la alteridad que es reducida al mismo tiempo que se le intenta incorporar como un «actor» más en el extenso paisaje de relaciones que proyecta la vida en sociedad (Dufour, 2002, p. 153, ss).

Tanto en los escritos narrativos como en los políticos, sociológicos e históricos es posible percibir en Lastarria un idealismo latente, cifrado en la célebre máxima «combatir la ignorancia», que va configurando una filantropía señera en las coordenadas latinoamericanas. En principio, resulta revelador que el intento de conseguir la unidad cultural, la ilustración del pueblo, su socialización y el «desarrollo de una conciencia pública» (Jocelyn Holt, 1985) no pasara por el silenciamiento de las voces disidentes, sino por el atento oído de las discursividades menores (Foucault, 1992) y por su socialización (Du-
3

El desmarcado permanente de los grupos de poder tradicionales llevaron a Lastarria a concebir incluso la fundación de un partido que tomara la bandera de la igualdad y la libertad con el encono y virulencia de él mismo. En Nota de uno de los Diputados de Rancagua al Gobernador de aquel departamento (1849), señala: «Este modo de ver las cosas me hizo esperar $y$ aún presentir la creación de un partido progresista, partido nuevo, extraño a los resentimientos i odios antiguos i sin mas interés que el nacional, ni mas principios que los de la verdadera filosofía. Para contribuir a su creación i a regenerar el orden de cosas que a la sazón dominaba, me hice opositor a todo lo que se hallaba de contrario a mis principios y en mis escritos de los cuales nunca negué i de los cuales no me avergüenzo, me di siempre por liberal. Jamás por pipiolo ni representante de partido alguno» (Lastarria, 1849 , p. 8).

4

El filósofo francés propone que esta díada locura/democracia se identifique con Logos y Sogol respectivamente, de esta manera en el transcurso del debate de ambos "personajes» se prestigia la locura como "razonable» y la democracia como su reverso, con lo cual llegamos nuevamente a la impracticabilidad del gesto social de oír, respetar y tolerar los rostros de la alteridad, aquellos que, al menos, tienen otra versión de la realidad. El fundamento político de la sociedad respondería a una lógica unaria, vale decir, aquella que promueve como su fin mayor la autorreferencia, por lo tanto el olvido de las instancias alternas que de existir ceden, para su perpetuación, a decir yo. "Efectivamente, todo se invierte cuando osamos definir el "yo» no mediante un otro, cualquiera que éste sea, sino mediante él mismo: pasamos así de una definición binaria del "yo" que corresponde al tipo «A está definido por $B » 0$ " $x$ es función de y» (en donde hay una relación entre dos términos) a una definición de un solo término o unaria del "yo», que es una proposición en la que el sujeto de la oración se repite en el predicado, como en el caso del "yo» en el enunciado "es yo quien dice yo" (Dufour, 2002, p. 29).

Filantropía, democracia, locura. Diario de una loca de José Victorino Lastarria JUAN D. CID HIDALGO 


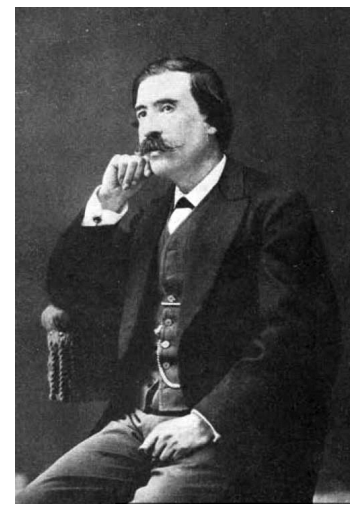

Lastarria.

5

En «Literatura regenerada, literatura nacional» leemos como sigue el juicio que el intelectual elabora respecto de las letras nacionales: «Pedro de Oña (...) escribió a fines del siglo XVI dos poemas de poco mérito literario, pero tan curiosos como raros en el día; el célebre Lacunza, Ovalle el historiador y el candoroso Molina que ha llegado a granjearse un título a la inmortalidad con la historia de su patria, son los cuatro conciudadanos, y quizás los únicos de mérito que puedo citaros como escritores; pero sus producciones no son timbres de nuestra literatura, porque fueron indígenas de otro suelo y recibieron la influencia de preceptos extraños》 (Délano, 1944, p. 8).

6

En el capítulo IX del texto de Dufour llamado «De la locura en la democracia de masas» leemos: «... esta tendencia mo derna no está demasiado lejos de renunciar a todo proyecto educativo en aras de un simple deseo de socialización del otro. Esa tendencia es paralela al proceso de reducción de la alteridad que caracteriza a las sociedades democráticas: puesto que el otro es como yo, no tengo que tener ningún proyecto educativo para con él y sólo puedo, en el mejor de los casos, ocuparme de su socialización» (Dufour, 2002, p. 153-154).

7

Las negritas corresponden al original.

Filantropía, democracia, locura Diario de una loca de José Victorino Lastarria

JUAN D. CID HIDALGO four, 2002) esto último, por cierto, generador -como veremos- de la paradoja.

Sin embargo, en «Discurso de incorporación a una Sociedad Literaria» podemos notar la otra cara de la moneda, vale decir, el afán homogenizador y disciplinador que traspasa toda su visión, en definitiva, politizada, del naciente Chile:

Escribid para el pueblo, ilustradlo, combatiendo sus vicios y fomentando sus virtudes, recordándole sus hechos heroicos, acostumbrándolo a venerar su religión i sus instituciones; así estrecharéis los vínculos que lo ligan, le haréis amar a su patria, lo acostumbraréis a mirar siempre unidas su libertad y su existencia social (Lastarria, 1842, p. 15).

La educación en general y la literatura en particular son a su modo de ver los vehículos de la ilustración deseada, dispositivos capaces de construir una imagen no solamente simbólica de país naciente con ganas de desarrollarse igualitaria y democráticamente ${ }^{5}$, sino también un mecanismo eficaz de transformación de la realidad. La zona paradojal que no percibe Lastarria es precisamente aquélla que nace de su pensamiento progresista y liberal, aquél que pretende la incorporación de la otredad en la conformación del país. Dufour, en este sentido, reconoce que junto a la medicina y otras prácticas sociales (como la literatura, por ejemplo) que pueden ser consideradas en el campo de la educación, no se ocuparían de ello, ni de curar, ni de sanar, ni de restablecer, sino más bien socializar los síntomas, con lo cual se generaliza al resto de los sujetos, decisión que eleva esa discursividad al rango de normalidad, elección que desencadena la reducción de la alteridad o derechamente su desaparición ${ }^{6}$.

El afán «ilustrador» y republicano de Lastarria va, en cierta medida, deformando su filantrópica tarea de combatir la ignorancia si pensamos, con Michel Foucault, que proponer es dominar: «Mi posición es que no tenemos que proponer. Desde el momento en que se propone un vocabulario, una ideología, que no puede tener sino efectos de dominación» (Foucault, 1994, p. 85). Es imposible entonces, escamotear los efectos de dominación que estos intentos liberales de consolidación democrática proyecta al futuro. El compromiso generalizado a que aspira Lastarria, vale decir, el respeto, validación e incorporación de los distintos «actores sociales» a su con- texto inmediato, de tal manera que florezca el orgullo nacional conditio sine qua non de una república libre, plural y moderna, engendra la construcción de una filantropía general en la génesis misma de la nación, «...nada será Chile, la América toda, sin las luces» (Lastarria, 1842 , p. 6), que ahora solidaria y humanista levante una nación organizada alrededor del afecto y el reconocimiento de sí.

Esta filantropía sostenida por Lastarria, más bien teórica que práctica, en que «decir» $\mathrm{y}$ «hacer» se distancian, queda suficientemente relativizada si consignamos que este pensador y político gozó de múltiples instancias de poder durante su dilatada vida pública $y$, por lo tanto, podría haber traducido el espíritu de sus ideas al diario vivir como al diario gobernar. En la selección de textos de Luis Enrique Délano, llamada Lastarria (1944), luego de un extenso prólogo del antologador encontramos «Literatura regenerada, literatura nacional» donde nuestro autor explicita la responsabilidad y la obligación de que se siente investido:

Otro apoyo más quiere la democracia, el de la ilustración?. La democracia, que es la libertad, no se legitima, no es útil, ni bienhechora sino cuando el pueblo ha llegado a su edad madura, y nosotros somos todavía adultos. La fuerza que debiéramos haber empleado en llegar a esa madurez, que es la ilustración, estuvo sometida tres siglos a satisfacer la codicia de una metrópolis atrasada y más tarde ocupada en destrozar cadenas, y en constituir un gobierno independiente. A nosotros toca volver atrás para llenar el vacío que dejaron nuestros padres y hacer más consistente su obra, para no dejar enemigos por vencer, y seguir con planta firme la senda que nos traza el siglo (Delano, 1944, p. 5).

La doctrina liberal impulsada por José Victorino Lastarria, consecuentemente con su espíritu dialógico y didáctico, desestima casi hasta la desaparición la verticalidad a que se estaba acostumbrado, donde las categorías tradicionales como gobernantes y gobernados, señores y siervos -por ejemplo-dan paso a la horizontalidad inclusiva que propone la díada patria/ciudadano. Este desplazamiento ejemplar donde los unos y los otros sienten que son necesarios para el funcionamiento y la coexistencia armoniosa de la sociedad nueva, en la cual las relaciones jerárquicas se den naturalmente, sin la necesidad de ejercer poder sobre sus integrantes, proyecta una 
concepción que deja en evidencia el utopismo propio del liberalismo decimonónico «...ya no funciona estrictamente mediante la mordaza y el silenciamiento del cuerpo, sino más bien con el proyecto -acaso nunca realizablede fundar su legitimidad, no ya en el castigo corporal, sino en el afecto del ciudadano que a cambio de la protección estatal internaliza y entraña a la ley» (Ramos, 1995, p. 25)8.

\section{Crisis, crítica, disidencia}

Diario de una loca es una novela problemática desde perspectivas varias. Desde la elección del tema, el tratamiento literario del mismo, la renuncia a explicitar y situar el desarrollo de la acción en las coordenadas geopolíticas del territorio chileno, su distanciamiento técnico de la escritura romántico naturalista del momento, hasta el juego sistemático con los planos temporales y la desorientación del personaje respecto de «ser» o «estar» loca, son algunos flujos generadores de este texto olvidado por la crítica, pero que define con toda propiedad la complejidad que asume el quehacer intelectual y el rol de la literatura nacional en la solidez esperada de un estado preocupado por sus componentes. Atendiendo a estas variables, la escritura lastarriana se desmarca de los convencionalismos imperantes tanto en el plano estrictamente literario como en el histórico e ideológico.

A todas luces, entonces, incluso antes del ejercicio de lectura, este texto se valida como discurso crítico que parte de la imagen de la enfermedad, tópico romántico por antonomasia, propuesto como una manera básica de segregación, hasta la expulsión del personaje previa a su reencuentro con la cordura, con la normalidad, cifra última de su muerte. Susan Sontag en La enfermedad y sus metáforas y el Sida y sus metáforas señala: «A todos al nacer, nos otorgan una doble ciudadanía, la del reino de los sanos y el del reino de los enfermos» (Sontag, 1996, p. 11) a lo que Eleonora Cróquer Pedrón en «Diario de una loca: hacia una representación otra de lo diferente» (1995) agrega que «... el texto de José Victorino Lastarria, en tanto parte del período en el cual se está configurando el imaginario nacional latinoamericano, presenta una factura ficcional alternativa que sugiere una ramificación del problema» (Cróquer, 1995, p. 82). En este complejo escenario de formación nacional y puesta al día de nuestras letras y su inserción en el contexto latinoamericano, la novela de Lastarria se inscribe como un diagnóstico de la intimidad que proyecta sus singularidades en una concepción histórica cuyo pretendido humanismo colisiona con las mismas estructuras de poder que originan la segregación y la expulsión de los rostros del otro.

Petra Arrea, la loca encerrada en un manicomio de Río de Janeiro, narra su experiencia en primera persona, en once de las trece secciones constitutivas del relato. Las últimas dos las conocemos a través de la narración de su doctor y amigo quien asume la responsabilidad de cerrar el texto, acción como veremos propia de las discursividades mayores que proscriben la disidencia. En términos estructurales, la construcción material del relato (flujo discursivo de la loca) es producto de una imposición terapéutica a que es sometida Petra como «tratamiento» para su presunta incompostura. La medicación impuesta consiste en la trascripción de las sesiones con el doctor, además de las conversaciones con la monja acompañante. Con esta actividad la enferma construye una especie de dossier con recuerdos de un pasado lejano en que se encontraría el origen de su estado. La dinámica de este tratamiento intenta mantener en un estado de vigilia permanente a la enferma que escudriña su pasado, descubre el desperfecto, lo confiesa en la sesión con el doctor quien diagnostica y prescribe la repetición de lo descubierto en el acto de escritura de Petra, que con este patrón exhibe su camino de dolor por el autoconocimiento.

La novela, entonces, queda fijada como el diario de vida de Petra, que registra su «yo dividido» (Laing, 1988) y cuya redacción revela el estatus que asume, no sólo el alienado, sino la estructura de poder que genera la exclusión aunque ésta se argumente-como ya lo hemos señalado- desde el humanismo y la filantropía. La relación entre estos dos elementos no es posible sino en la violencia -sugerirá Franco Basaglia en Razón, locura y sociedad (2006), texto que recalca que el sujeto otro es producto de «la marginación del que no acepta la problemática de la violencia institucionalizada que gobierna a nuestra sociedad» (Basaglia, 2006, p. 17)-, por lo tanto lo que subyace y determina la lógica del encierro, en términos del antipsiquiatra italiano, es una lógica punitiva por sobre la lógica terapéutica que sostendría el saber médico?.

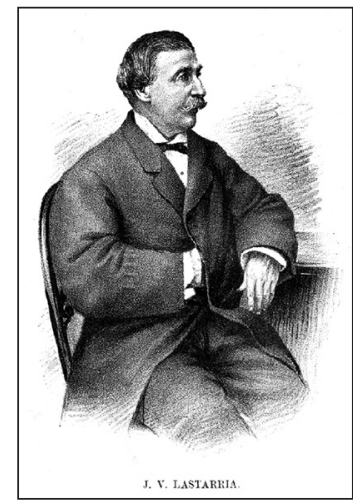

Lastarria.

Citado por Ximena Troncoso en «El retrato sospechoso: Bello, Lastarria y nuestra ambigua relación con los mapuche» (2003).

Para Basaglia cárcel y manicomio son instituciones de la violencia y para explicar su apreciación recurre a un ejemplo digno de tener en cuenta. $\mathrm{Si}$ un alcohólico se encuentra encerrado en un manicomio, la terapia que recibe es el encierro, obligarlo a no salir y a sentir miedo de él. Si este sujeto saliera por un mes, durante ese tiempo no beberá porque "asimiló la agresión, la violencia del manicomio» (Basaglia, 2006 , p. 20). Como es de esperar la brutalidad es mayor con los sujetos alienados, por tanto prácticamente la única salida del enfermo es la muerte. 
10

Ximena Troncoso en «El retrato sospechoso: Bello, Lastarria y nuestra ambigua relación con los mapuche» (2003) realiza un pormenorizado análisis de la presencia del mapuche en el discurso progresista de $\mathrm{Be}$ llo y Lastarria, para quienes el mapuche sirve de contraste metodológico y no como actante ciudadano, incorporado en la sociedad blanca con su valor particular. La profesora Troncoso define como sigue este intento interesado de inclusión que no termina sino en exclusión: "Bello y Lastarria, las principale figuras de la intelectualidad del período de constitución de la nacionalidad chilena, incorporan lo indígena porque les proporciona el referente diferenciador, la originalidad tan ansiada. Pero en lugar de potenciar lo indígena y buscar una alianza cultural, se lo supedita a un proyecto del que los mapuche $y$ todo otro pueblo indígena están excluidos. A través de los textos de estos escritores asistimos a los orígenes, en este caso literarios, de nuestra contradictoria identidad cultural: la inclusión simbólica y la exclusión concreta de los mapuche en y de la sociedad chilena» (Troncoso, 2003, p. 173).

11

En «Literatura regenerada, literatura nacional» Lastarria reflexiona acerca de lo expuesto de la siguiente manera: "¿iPero cuál ha sido, cuál es en el día nuestra literatura? ¿A dónde hallaremos la expresión de nuestra sociedad, el espejo en que se refleja nuestra nacionalidad? Aterradora es por cierto la respuesta a una pregunta semejante; pero así como rompe con audacia su vuelo la simple avecilla, después del espanto que le causa la explosión mortífera del arcabuz del cazador, romperemos nuestra marcha después del terrible desengaño que nos causa la idea de nuestra nulidad, cuando veamos que necesitamos formarnos con nuestros propios esfuerzos» (Délano, 1944, p. 7). El influyente intelectual chileno apuesta todas las fichas a las capacidades de la masa crítica chilena en la constitución de la nueva nación.

Filantropía, democracia, locura Diario de una loca de José Victorino Lastarria JUAN D. CID HIDALGO
El diario/delirio de Petra cristaliza en el fluir de la conciencia, en constantes flash backs, escritura automática, fundido y cruce de planos temporales que se tropiezan en su afán por salir y exhibir su verdad, cuestión que interrumpe el flujo discursivo central de la mujer que va acentuando algunos aspectos en la medida que se suman intensidades y trazos experienciales que dejan entrever su historia particular, privada e íntima, además de ir develando otra realidad, más compleja y posiblemente más pública, y por lo tanto relacionada con el bien común, la democracia. Beatriz González, en «Del liberalismo romántico al idealismo solipsista. «Diario de una loca» (1875) de José Victorino Lastarria» (1986), señala «... la historia de Petra -basada en la vida de un presidente de Bolivia-, que se va reconstruyendo progresivamente, da paso a un discurso de carácter analítico, cuya función trasciende la historia privada de la protagonista» (González, 1986, p. 30), su testimonio entonces es metonimia de su/nuestro país. La historia de su locura, el quebrantamiento de su yo razonable producto del «loco amor» por Fructuoso marcan el sino de Petra a quien se le condena al encierro (manicomio de Río de Janeiro) y a trabajos forzados (escribir sus memorias, su diario... de vida). En este sentido la misma Petra señala:

Los años no habian bastado. La edad habia sido ineficaz. ¿Pero que pueden los años, ni la edad, cuando se ama a una sombra ensangrentada, cuando se ama a un cadáver destrozado en medio del bullicio i de la curiosidad de un pueblo? ¿Es ese un amor que se apaga, un amor que se olvida? ¿Hai algo en el mundo, algo en la vida, que sea capaz de hacer olvidar la imájen de un patíbulo? (Lastarria, 1885, p. 216-217).

La exhibición de su fuero interno deja en la indefensión a la loca quien a modo de vía crucis va purgando episodio tras episodio, a través de la impresión en la letra, su culpa: la incapacidad de absorber el disciplinamiento de que fue objeto. De este modo la enferma va purificando y despojándose de aquello que la ha llevado a la corrupción del yo, proceso que no culminará sino hasta su expulsión. Las correcciones entonces son favorecidas por el acto de escribir, de encerrar en ese código el conjunto de disciplinamientos no logrados que la han convertido en infame.

La novela de Lastarria transita, al menos en una reducción general, entre dos dimensio- nes cuya complementariedad suscribe un paso importante en el progreso de la novela, o al menos de la protonovela, en el último cuarto del siglo XIX. Por un lado, el texto trabaja sobre el tópico de la enfermedad, extensamente tratado bajo el naturalismo literario en boga, a la vez que acentúa el tratamiento del personaje obnubilado por la oscuridad y el descrédito de sus propias facultades como garantes del equilibrio emocional. Tratamiento que inscribe plenamente al texto y su autor en el mapa literario de aquella época. Sin embargo, la incorporación de elementos novedosos en la construcción de la novela (multiplicidad de foco narrativo, alternancia de planos temporales, supresión del criollismo, etc.) va definiendo el texto como «una obra extraña dentro del contexto hispanoamericano» (González, 1986, p. 29), fundamentalmente porque es generada a propósito de una necesidad histórica de la que se hace parte Lastarria al asumir un rol de intelectual iluminado. Esta autodefinición de su labor social, al proponerse como la voz de los sin voz capaz de fabular simbólica y modélicamente el mundo, «inclusión simbólica y exclusión concreta» dirá Ximena Troncoso $(2003)^{10}$, demuestran precisamente que esa capacidad de escribir/ nombrar, referir y construir la realidad visibiliza aquellos lugares cerrados donde se ha desplazado a los diferentes rostros del «otro». Lastarria intenta, desde la razón liberal y progresista, construir una cesura, un espacio intersticial virtual donde sea posible coexistir con la diferencia fundando así las bases de una nación ideal plural con más de una esperanza en el porvenir y capaz de generarse a sí misma ${ }^{11}$.

Como vemos este afán humanista, "plan de ataque contra los vicios sociales» dirá el mismo Lastarria, queda interrumpido desde el momento mismo que se justifica como alternativo al modelo criticado ya que el cambio significa un avance en la forma y no en el fondo del manejo de ese ideal de nación permanentemente buscado por conservadores y liberales.

A partir de un juego de perspectivas alternadas, Lastarria insiste en denunciar los excesos del racionalismo conservador que se ha ido constituyendo en una minoría poderosa capaz de sancionar, excluir y paralizar aquello que pueda entrar en polémica con su capacidad estatal. «i I esa es la mansión de un pueblo de cuerdos, que ha construido en este sitio un 
palacio para sus locos! ¿Adónde está la razón, allá o aquí?» (Lastarria, 1885, p. 198) declara la novela en el comienzo del cuarto flujo discursivo del diario de Petra, quien vislumbra el complejo entramado de relaciones entre poder y locura, entre la preocupación estatal y la incorporación de las minorías. La escritura lastarriana, entonces, aparece coherente con el intento de iluminar el saber minoritario de aquel grupo signado como enfermo, que con la asunción de la voz de la loca, denuncia, critica y relativiza las prácticas sociales en ejercicio a finales del XIX. El egoísmo, cuestionado en primera instancia, es apenas superficial si pensamos que la crítica artera es a la supuesta filantropía de este grupo razonable y conservador que pretende salvaguardar el orden de una sociedad generada y pensada a partir de la disciplina y el control que definitivamente solidifican su estructura de dominación:

¿Adónde está la razón, allá o aquí? Allá, si la razón consiste en ajustar la vida a las conveniencias del egoismo i a las exigencias de la sociedad: aquí, si únicamente tienen alma los que saben pensar i sentir sin egoismo, sin esclavitud, sin miedo, sin estupidez. ¡La humanidad no piensa, i se llama racional i se dice la reina del mundo! Solo piensa una mínima porción, $i$ de esos que piensan, los unos no hacen mas que estudiar el modo de esclavizar el espíritu i de sujetar a la sociedad a un sistema de ideas i de intereses, propio para dominarla: los demas que piensan, i no piensan de ese modo, son locos.

Pero todos sienten i se dejan llevar de sus instintos. El que sabe gobernarlos en provecho propio, saciándolos en secreto, i disimulándolos en público, para ajustarse a las conveniencias de la sociedad, ese es cuerdo. En eso consiste la racionalidad, la superioridad del hombre (Lastarria 1885, p. 198-199).

El deliberado e insistente interés por probar los excesos de una concepción conservadora de la realidad importuna al lector en tanto que el discurso novelesco propuesto deviene proselitismo ideológico, con lo que se pierde lo ganado en la discusión real acerca de la visibilidad y audición de un saber minoritario. Dicho de otro modo, la posibilidad de liberar un saber alterno como el de Petra, sin compartir, o al menos, tolerar su «versión» de la realidad, queda desplazado por el constante discurso liberador del progresismo amparado por José Victorino Lastarria. Beatriz González, en el texto antes citado, percibe este juego de discursividades sin acentuar la dimensión que hemos expuesto. La investigadora señala:

La racionalidad que se está poniendo en juego -desde la perspectiva ideológica del discurso- es la que permite un estado social para el desarrollo de la libertad individual, sobre todo de pensamiento, y un estado político representativo; en otras palabras: la apelación a la racionalidad de los valores liberales del proyecto de las nuevas repúblicas (González, 1986, p. 36).

Diario de una loca se articula fundamentalmente a partir del discurso de la mujer desequilibrada cuya materialidad pone en tensión dos esferas tradicionalmente opuestas. Por un lado, el texto es registro de una discursividad cuyo soporte es esencialmente oral (discurso dislocado y delirante) pero, por otro lado, la novela impone disciplina sobre este torrente de origen oral al violentarlo en pos de su inscripción en el diario (instancia de confesión). Vale decir, el proceso de disciplinamiento a que es sometido el personaje consiste en la canalización del flujo oral delirante en las casillas particulares de las letras de molde. En este sentido podemos observar que el carácter curativo del acto de escribir (disciplinamiento) tiene su correlato en que la escritura de la novela también ha sido instancia de conjuración de la otredad. El camino recorrido por Petra, en los 11 capítulos que ella escribe/ confiesa, no significan nada si su relato ahora no es completado desde la razón técnica más sancionadora: la razón médica ${ }^{12}$.

El discurso crítico, cuya impronta manifiesta juicios cargados de lucidez y coordinación, es instalado en boca de uno de los perturbadores sociales por antonomasia: el loco/a, a quien se le adosan al menos un par de semas que agudizan su ejemplaridad en este entramado de relaciones. Por un lado, su género, la loca es mujer, y por otro, la cercanía de su discurso con los valores de la revolución.

Petra, mujer, loca y revolucionaria va desplegando sistemáticamente sus reproches a propósito de la pérdida de foco del sistema social conservador, materialista y burgués, que se ha valido de un discurso falaz para mantener en compartimentos estancos las virtuales expectativas de país hacia el porvenir. En este sentido, Petra encarna el reverso de su crítica, se erige como ejemplar ya que ella, como en el clásico mito de Casandra, percibe el futuro pero es desoída por los ciudadanos ${ }^{13}$.
12

Recordemos por un momento las proposiciones de Robert Caste en el capítulo quinto de El orden psiquiátrico (1980), «De la psiquiatría como ciencia política», en este influyente trabajo señala: «Por tanto, la medicina mental genera la exclusión social. Pero le da la más "humana» de las formas justificando médicamente sus razones y tratando médicamente sus efectos. Al menos algunos de los alienistas de siglo XIX tuvieron el mérito de ser conscientes. Practicaron este humanismo, la devoción por lo enfermo, la competencia técnica, cualidades profesionales indispensables, ciertamente, pero que tienen sentido a partir de la aceptación de un mandato social que subordina esta profesión a una experiencia política: «Si el individuo tiene derechos, también la sociedad tiene los suyos (...). El loco amenaza a la sociedad con los peligros de trastornar el orden público y comprometer la seguridad de las personas. Por tanto, que pierda su libertad individual cuando ponga en peligro esos bienes; nada es más justo» (Castel, 1980 , p. 212).

13

No debemos olvidar que en la antigüedad grecolatina predomina una concepción olímpica de la locura, es decir, que sería una especie de castigo de los dioses, o inspiración de los mismos o posesiones del cuerpo. En este sentido la figura paradigmática de esta concepción es Casandra, mujer a la cual se le condenó a conocer y profetizar el futuro pasando por loca frente a quienes la escuchan. Cuenta la historia que Apolo le otorga a Casandra el poder de adivinación (los dioses hablaban por ella) y cuando éste es engañado por la mujer, condena a la adivina a que sus palabras suenen como mentira frente a sus coetáneos quienes la tildan de loca.

\footnotetext{
Filantropía, democracia, locura. Diario de una loca de José Victorino Lastarria JUAN D. CID HIDALGO
} 


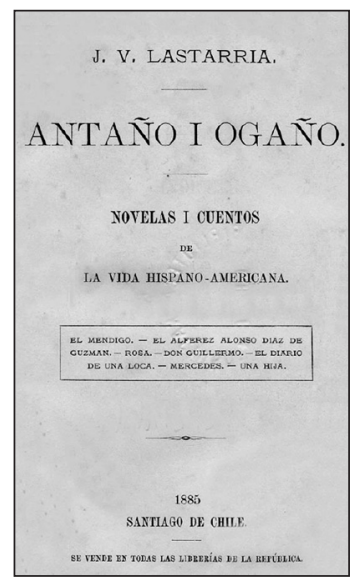

Cubierta Antaño I Ogaño.

14

En Van Gogh el suicidado por la sociedad, la posición de destacado dramaturgo francés es aún más categórica "En el alienado hay un genio incomprendido que cobija en la mente una idea que produce pavor, $y$ que sólo puede encontrar en e delirio un escape a las opresiones que le prepara la vida» (Artaud, 1994, p. 90).

Filantropía, democracia, locura. Diario de una loca de José Victorino Lastarria JUAN D. CID HIDALGO
Dany-Robert Dufour dirá «el loco no siempre está loco» (Dufour, 2003, p. 116).

\section{Confesión de parte. Verdad atribuida}

Detengámonos un momento en las relaciones que se producen entre confesión y verdad para explicarnos el funcionamiento de la exclusión de la loca vidente. El presente de la escritura de Petra actualiza el acto de confesión que a su vez reconstruye y escenifica el recuerdo huidizo del personaje que se va sobredisciplinando lentamente con el acto de manuscribir el diario, que progresivamente va iluminando las zonas intersticiales y originales de su memoria dislocada. El despliegue de cierta tecnología de la confesión (Foucault, 1996) subraya la zona de vecindad entre locura y verdad, entre locura y saber; por cuanto su lectura pone en juego la búsqueda y la exploración de ella con el fin de exhibir su saber particular. En definitiva, la locura de Petra Arrea deviene vehículo de la verdad, aquella insoportable a los oídos del grupo distribuido en las coordenadas del centro. Con Artaud ${ }^{14}$ «un alienado es en realidad un hombre al que la sociedad se niega a escuchar, y al que quiere impedir que exprese determinadas verdades insoportables» (Artaud, 1994, p. 77)

La mujer loca, condenada al encierro y forzada a escribir su diario como terapia para recobrar la cordura, subvierte el contenido punitivo de su condición en el momento en que se entrega a la locura y accede recorrer el camino hacia la verdad pura en que los dispositivos del poder, cuya «ideología punitiva» (Basaglia) se sostiene en la filantropía médica, no despojan al sujeto de la posibilidad de pregonar una razón distinta, una lógica otra. La locura de Arrea, a la luz de lo planteado antes, puede ser entendida como una entrega al conocimiento, como posibilidad de sacudirse de sus humores ingresando a esta zona de libertad en que la diferencia sí es posible y donde la disidencia no es condenada sino alimentada, y que inexorablemente desemboca en el conocimiento de sí. Con Foucault comprendemos que si la verdad se opone al poder, entonces, su descubrimiento podría eventualmente llevarnos a la libertad.

La actualización de los retazos experienciales, de las líneas entrecortadas de la memoria en que la narración de su matrimonio, el hijo perdido, la muerte del marido, el intenso amor a Fructuoso y el examen del pasado, favorecen la aparición de uno de los aspectos importantes en la consecución de la salud: el conocimiento de sí. De esta manera se justifica suficientemente el constante trabajo con la memoria, la búsqueda incesante de la verdad, intento de sobredisciplinar a Petra pero a la vez consecución de la verdad, de la libertad, condiciones que van apareciendo alternativamente en el desarrollo del relato. El carácter iluminado que por momentos ostenta Petra va desarticulando las certezas de que el poder ha dotado a la realidad. Las cualidades premonitorias de Arrea se declaran apenas comenzado el diario/delirio. Ella cifra la ambivalencia del manicomio en su lengua dislocada, que, no olvidemos, explicita verdades insoportables. "iAh! Estoi libre, sola ;.... Pero no, esa monja horrible, mi guardian, está allí. Está tranquila merced a mi estúpido sueño, i no estoy libre. Esa pesada puerta está con llave, ni es posible moverla siquiera. Pero la ventana ¡oh, que alegría! ¡De par en par!» (Lastarria, 1885, p. 189). Más adelante esta discursividad quiebra un eje fundante de la presunción de normalidad cuando la iluminada «ve» que la locura se encuentra instalada en el otro lado, en los espacios abiertos en que se reúnen y conviven aquellos sujetos disciplinados y distribuidos regularmente en el tiempo y en el espacio. «¿Por qué no aislan también las ciudades? ¿No son todos locos? ¡Oh, sí, el mundo también está aislado! Será porque está habitado por locos» (Lastarria, 1885, p. 195).

Las iluminaciones de Petra entran en conflicto con los síntomas de la locura, que como dijimos con Dany-Robert Dufour van siendo socializadas con lo que se logra la desaparición del yo. Dichas iluminaciones se desdibujan al aparecer esporádicamente cortando los flujos de su delirio, alucinaciones, descontrol general, fiebre, etc., sin embargo, desencadenan un grito intensísimo en que la disidencia de Petra deviene argumento de la verdad, descubierta al precio del desvarío:

¡I esa es la mansion de un pueblo de cuerdos, que ha construido en este sitio en palacio para sus locos! ¿Adónde está la razon, allá o aquí? Allá, si la razon consiste en ajustar la vida a las conveniencias del egoismo i a las exijencias de la sociedad: aqui, si únicamente tienen alma los que saben pensar i sentir sin egoismo, sin esclavitud, sin miedo, sin estupidez (Lastarria, 1885, p. 198). 
Esta alocución desestabilizadora, expuesta en la cuarta parte del diario, sitúa el relato en una región polémica, que cifra la incomprensión de los saberes oficiales respecto al saber encarnado por los distintos nombres de lo otro, con lo cual relativiza los estados de salud y enfermedad del grupo a que pertenece, crítica que parece ser permanente en los textos que ponen en juego los distintos rostros y discursividades menores. Más adelante descarga con mayor crudeza su percepción de la manera en que el funcionamiento social es posible a pesar de los perturbadores:

¡La humanidad no piensa, i se llama racional i se dice la reina del mundo! Solo piensa una mínima porcion, $i$ de esos que piensan, los unos no hacen mas que estudiar el modo de esclavizar el espíritu i de sujetar a la sociedad a un sistema de ideas i de intereses, propio para dominarla: los demas que piensan, i no piensan de ese modo, son locos (Lastarria, 1885, p. 198).

En cierto modo, con estas palabras la pluma lastarriana sentencia el descrédito de la sociedad latinoamericana en su incipiente constitución como estados nación modernos. Con ello evidencia la sistemática segregación que los distintos estados realizan, sobre todo aquéllos que profesan el conservadurismo como política de consolidación democrática. $\mathrm{El}$ adelantado escritor, al incorporar su texto en este escenario, propicia la lectura del Diario de una loca como un ejercicio crítico de las sociedades que silencian a sus disidentes a partir de la descalificación simbólica que elimina la posibilidad de diálogo e intercambio argumental de aquellos sujetos menoscabados y sometidos. De esta manera aparece perfectamente razonable la utilización del discurso de la loca como una línea de relativización de los valores imperantes, donde la locura aparece ligada al entusiasmo y la pasión por la justicia y la libertad, elementos fundantes de cualquier discurso crítico.

En el texto que nos ocupa, la crítica se origina a partir de la exhibición del sujeto menor cuya lengua desprovista de razón profiere esas verdades insoportables en el transcurso del proceso de reconversión a que es sometido. A lo largo de la lectura del diario, podemos rastrear aquella historia movediza que se desplaza entre el territorio familiar y político, que ha desembocado en la inadecuación existencial del sujeto para quien la incapacidad de olvidar lo inscribe permanentemente en la disidencia, esto aunque el texto plantee su acto de enunciación (confesión) como la cura de su desorden simbólico. «-¡Bien! Esclamó. Dejadla escribir sor María. La pluma, el llanto y el sueño van a curarla pronto...» (Lastarria, 1885 , p. 202)... «No, no os alarmeis, sor María. Entrad sin cuidado. No estoi loca. Hablaba sola, porque estoi escribiendo lo que hablo.» (Lastarria, 1885, p. 195) y más adelante inclusive otorga ese estatus de confidente/ confesor al médico con lo cual se transforma inusitadamente en garante de la normalidad y por lo tanto del equilibrio social:

Ayer estuve mal. Los recuerdos que escribi el dia anterior me hicieron daño. El doctor ha estrañado mucho el quebranto, i como es mi conconfidente, tuve que confiarle la causa. Leyó i me consoló. El quiere que me habitúe a hacer estos recuerdos con tranquilidad, que tenga valor i serenidad para afrontar el pasado. Su conversacion me ha fortalecido, i él me ha prescrito que la narre aquí: es su receta (Lastarria, 1885, p. 206).

Con el consentimiento del «enfermo», entonces, y su reconocimiento del dispositivo médico sobre su cuerpo comienza el proceso de reconversión del disidente, quien se ha transformado en un «animal de confesión» (Foucault, 1996, p. 74-75) De esta manera la confesión de Petra forma parte de lo que Foucault llama núcleo de la penitencia ${ }^{15}$, idea que subraya el carácter clave del acto de inventariar las faltas (expulsarlas del yo, expelerlas y eliminarlas), que en el caso que nos ocupa se enclavan en el pasado más recóndito de Petra, cuya exhibición y encierro en las palabras que componen el relato del diario, van aliviando y curando a la enferma, a la vez que la llevan a la desaparición.

La loca encerrada en un manicomio de Brasil, marginada por significar un peligro para la sociedad -aun cuando el principio filantrópico que subyace al encierro es la búsqueda de la cura del sujeto-, descubre su dimensión ejemplar en que la locura deviene verdad, fundamentalmente, porque las tecnologías de confesión se inscriben en el marco del conocimiento de sí (Foucault, 2003) en cuanto es un acto de exteriorización de la intimidad que adosa a su dimensión privada, la dimensión pública. Eleonora Cróquer Pedrón, en el texto antes citado, señala: «Entonces, se nos plantea la locura como figura simbólica de aquél que ha sido marginado por su pureza
15

En Los anormales. Curso en el Collège de France. 1974-1975 (2000), Michel Foucault señala que a partir de la Edad Media y durante la Reforma, la confesión (tarifada) comienza a inscribirse en el centro de la práctica de penitencia. Debido a que cada falta grave requería una reparación, se hizo necesario el ejercicio de inventariar y confesarlas.

Filantropía, democracia, locura Diario de una loca $\mathrm{de}$ José Victorino Lastarria JUAN D. CID HIDALGO 


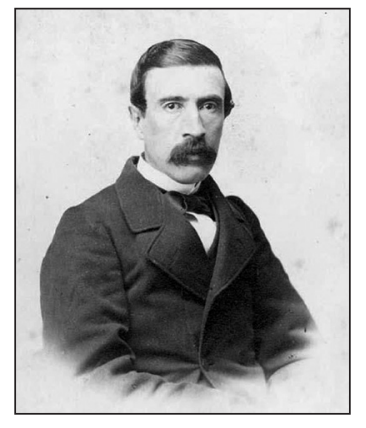

Lastarria.

16

La antipsiquiatría nos ha entregado una serie de instrumentos para "pensar de otra manera» las relaciones sociales condicionadas por el poder y su justificación democrática basada en el bien común de la mayoría, colectivo capaz de instaurar un or den para quienes comparten su «lucidez» como para los otros. Para esta corriente nueva, que reconoce como mentor a Miche Foucault, las sociedades modernas han desplazado los antiguos métodos de normalización como el convento, la cárcel (panóptico), el hospital, la familia (Lettres de Cachet), etc. por la amigable inserción en espacios bucólicos donde el esparcimiento, sumado a una preocupación casi hogareña, logra recuperar a los enfermos que se habían disociado del mundo. "Pabellón 21» de Londres, es el nombre dado por Cooper a la clínica donde practica el ejercicio antipsiquiátrico, como práctica alternativa a la psiquiatría tradicional, frente a la violencia institucional cuestionando el hospital, yendo más allá de la comunidad terapéutica, en una práctica que ensaya un clima de libertad para los pacientes, sin violencia ni restricciones.

\section{7}

Recomendamos la lectura de Utopía y mentira de la novela panóptica (2006) texto en que los autores conciben el género novela como forma de poder disciplinario en que se despliegan jerarquías, vigilancia, inspecciones y escritura. Razón por la cual los investigadores llegan a concluir, entre otras múltiples zonas de interés, que "todo e aparato discursivo de la máquina narrativa es irremediablemente panóptico». (Rodríguez et. al., 2006, p. 12)

Filantropía, democracia, locura. Diario de una loca de José Victorino Lastarria JUAN D. CID HIDALGO ideológica, la rectitud de sus principios y la rebeldía ante la corrupción» (Cróquer, 1995, p. 85). Tras la confesión, tras la escritura del diario se esconde la verdad, tras la novela se esconde la verdad, una verdad que se oculta tras los signos, las noticias, las distorsiones, los hechos y la apariencia de realidad configurados por las leyes particulares del poder que se intenta desestabilizar.

Esclarecedora en este sentido es la sección ocho del relato donde asistimos a una declaración contundente del personaje quien percibe que el tratamiento a que ha sido sometido es equivalente a su capacidad de subversión:

No sé cuánto tiempo habia pasado encerrada, sin mas asistencia que la de dos cholas, que cuidaban de mí, i que a menudo lloraban conmigo... Decian que estaba loca. Tomaban por locura mi dolor; pero era porque no se queria que mis lamentos revelasen la verdad. Al fin me sacaron a la sociedad. ¿Seria porque habia dejado de lamentarme? Talvez. Ya entónces mi dolor era mudo, impotente, resignado, no hacia daño...

En la sociedad, fuí muda. Tenia la relijion del dolor i me encerraba para rendirle culto, el culto de mis lágrimas. Todos me compadecian, i no disimulaban su compasion. Cada cual se esmeraba en protestarme sus buenos deseos. ¡Qué consuelo! El desgraciado sabe bien lo que valen los buenos deseos de los felices. Le dan risa. Solo estima las simpatías de otros desgraciados (Lastarria, 1885, p. 212).

La verdad, el acceso a ella a través de la condena al sufrimiento del cuerpo por el encierro, se explica básicamente porque «el cuerpo interrogado en el suplicio es a la vez el punto de aplicación del castigo y el lugar de obtención de la verdad» (Foucault, 2004, p. 48). El texto nos presenta la inadecuación de Petra con su entorno inmediato, por tanto su enfermedad no es producto de la incapacidad de «reinscribirse en la práctica social» (Cróquer) sino que en la adecuación a las condiciones enfermizas de la sociedad conservadora, burguesa, catolizada y que ha perdido el interés por el bien común, a favor de mantener el inmovilismo social, intelectual, cultural, etc., elementos peligrosos y portadores de posibles fisuras revolucionarias que desestabilicen el poder central. David Cooper, en Psiquiatría y antipsiquiatría $(1974)^{16}$, sostiene que «la locura no está en una persona, sino en un sistema de relaciones de lo cual forma parte esto que llamamos paciente». Beatriz González en el texto antes citado percibe esta misma dimen- sión cuando señala que «la sociedad enferma extiende su afección a los individuos. De este modo la «locura» de Petra es, por una parte, el resultado simbólico del trastocamiento del orden natural de una sociedad, y, por otra, la instancia que permite calibrar el estado de corrupción de las sociedades de ese momento ante la pérdida de una serie de valores que encarnan los ideales de libertad y patriotismo correspondientes al pasado independentista.» (González, 1986, p. 37) El mismo Michel Foucault en su Historia de la locura... (1998) descubre que la locura sufrió un proceso de institucionalización a fines de la Edad Media que la llevó al terreno de la medicina, otorgándole la categoría de amenaza, infracción y descompostura, por lo tanto, susceptible de ser curada. Es por esto que cobra tanta importancia el acto de escribir el diario, porque a través de él queda en evidencia el distanciamiento del sujeto imperfecto desde el punto de vista disciplinario cuya presencia descontrola el flujo discursivo de Petra que a su vez desencadena la fragmentación de su yo, desorientado en el cúmulo de información (historias, vivencias, experiencias) que va marcando la angustia, dolor, desamparo e indefensión del sujeto que a pesar de toda esta trama del poder puede alternativamente ir «viendo» e iluminando aquellas zonas que desfavorecen la unidad y la igualdad de los hombres.

En 1842, 33 años antes de la publicación de Diario de una loca, Lastarria ya había percibido dicha dimensión en el discurso a la sociedad literaria cuando -desde la vereda del orador- explicita su preocupación por el bien común y las debilidades de la democracia, diagnóstico que cierra con una tarea a realizar en conjunto. El país debe generar no solamente políticos de excepción sino también escritores, hombres de cultura que puedan iluminar con su sapiencia el camino que Chile debe seguir en pos del futuro:

... reunirse en torno de esa democracia que milagrosamente vemos entronizada entre nosotros, pero en un trono cuya base carcomida por la ignorancia, se cimbra al mas lijero soplo de las pasiones, y casi se desploma, llevando en su ruina nuestras mas caras esperanzas (Lastarria, 1842, p. 6).

El diario de Petra, la novela de José Victorino Lastarria, no puede renunciar a la razón de su ser, disciplinar ${ }^{17}$. Aun cuando los obje- 
tivos sean libertarios, la novela se cierra tras la muerte, la expulsión del perturbador que a pesar de todo ha denunciado y proferido la verdad. En términos de Franco Basaglia, Petra «asimiló la agresión» sistemática del entorno. Su escritura, actividad iluminadora y condenatoria a la vez, decreta la suerte de la mujer cuya lápida es puesta por la razón científica respaldada por el doctor. En este sentido nos parece significativa la escena en que se manifiesta el afán disciplinador cuando pronuncia, desde la benignidad de su saber técnico, juicios doloridos y compasivos respecto de la tarea de la enferma que con su muerte deja su historia inconclusa «voi a continuar su diario» (Lastarria 1885: 218) anuncia el doctor dejando de lado la reacción esperada de su parte como portador de la razón científica capaz de medicar a la enferma. Por el contrario, su argumentación se desplaza al terreno sentimental que desprestigia y subvalora la alteridad «Ella tendrá el placer de ver trazado por mí su terrible diálogo, cuando mejore. Talvez, leyéndolo una i otra vez, a mi lado, con mis consuelos i reflexiones, se acostumbre a afrontar su espantoso recuerdo" (Lastarria, 1885, p. 218). El intento final, esa fracción de tiempo en que vuelve a la cordura cifra al instante su desapego del lenguaje, aquel único principio que la mantenía ligada a la realidad, y por lo tanto, adviene la muerte: «Su voz se apagó. Su busto cayó dulcemente sobre el lecho. Era un cadáver...» (Lastarria, 1885 , p. 222). Con esta imagen romántica de sanación y purgación del mal finaliza el texto, su recorrido por los inaudibles territorios del despojo.

Diario de una loca, a la luz de lo expuesto en estas páginas, modela ejemplarmente la disociación permanente entre una construcción filantrópica sustentada en la voluntariedad genuina de quien desea una sociedad humanitaria, libre y democrática pero se encuentra con un entramado de redes de poder que no permite sino la asunción de su verdad, sus deseos, su ambición. José Victorino Lastarria y su proyecto de reconstrucción de la historia basado en la búsqueda de la libertad, cuya finalidad última es abrir el relato histórico, no sólo para cuestionar el presente sino también para incorporar a los diferentes, no puede dejar de ser una ilusión. Claro está que no entendida en términos peyorativos o de consuelo, sino entendida desde la vereda de la positividad, vale decir, como la puerta abierta para pensar desde el principio esperanza, desde el trabajo con la utopía aun sabiendo su irrealizabilidad pero creyendo profundamente que es una forma de pensar de otra manera la construcción de ese pueblo que falta.

\section{Bibliografía}

Artaud, Antonin (1994), Van Gogh el suicidado por la sociedad, Buenos Aires, Editorial Argonauta.

Basaglia, Franco (2006), Razón, locura y sociedad, Madrid, Siglo XXI Editores.

Castel, Robert (1980), El orden psiquiátrico, Madrid, La Piqueta.

Cooper, David (1974), Psiquiatría y Antipsiquiatría, Buenos Aires, Paidós.

Cróquer Pedrón, Eleonora (1995), «Diario de una loca: hacia una representación otra de lo diferente», Revista de Literatura Hispanoamericana 30 , pp. 79-88.

Délano, Luis Enrique (1944), Lastarria, México, Edición de la Secretaría de Educación Pública.

Dufour, Dany-Robert (2002), Locura y democracia. Ensayo sobre la forma unaria, México, Fondo de Cultura Económica.

Foucault, Michel (1992), Geneaología del racismo, Madrid, La Piqueta.

- (1994), Un diálogo sobre el poder y otras conversaciones, Madrid, Alianza.

- (1998), Historia de la locura en la época clásica, México, Fondo de Cultura Económica.

- (2000), Los anormales. Curso en el Collège de France (1974-1975), México, Fondo de Cultura Económica.

- (2003), Historia de la sexualidad: la voluntad de saber, México, Siglo XXI.

- (2004), Vigilar y castigar. Nacimiento de la prisión, Argentina, Siglo XXI.

Franco, Jean (1985), La cultura moderna en América Latina, México, Grijalbo.

González, Beatriz (1986), «Del liberalismo romántico al idealismo solipsista. Diario de una loca (1875) de José Victorino Lastarria», Revista de Crítica Literaria Latinoamericana 23, Año 12, pp. 27-44.

Laing, Ronald (1988), El yo dividido, México, Fondo de Cultura Económica.

Jocelyn Holt, Alfredo (1985), «El desarrollo de una conciencia pública: Lastarria y Sarmiento», Estudios Públicos 17, pp. 213-233.
Filantropía, democracia, locura. Diario de una loca de José Victorino Lastarria JUAN D. CID HIDALGO 
Lastarria, José Victorino (1842), Discurso de Incorporación de D. J. Victorino Lastarria a una Sociedad Literaria de Santiago, en la sesión del tres de mayo de 1842, Valparaíso, Impr. de M. Rivadeneyra.

- (1849), Nota de uno de los Diputados de Rancagua al Gobernador de aquel departamento, Santiago, Imprenta Chilena.

- (1885), Antaño i Ogaño. Novelas i cuentos de la vida hispano-americana, Leipzig, Imprenta de F. A. Brockhaus.

Ramos, Julio (1995), «Lengua y ciudadanía en Andrés Bello", Revista de Crítica Cultural 10 , pp. 20-29.
Rodríguez, Mario y Triviños, Gilberto (edit.) (2006), Utopía y mentira de la novela panóptica, Chile, Editorial Universidad de Concepción.

Silva Castro, Raúl (1957), Los recuerdos literarios de Lastarria, Santiago, Zig Zag.

Sontag, Susan (1996), La enfermedad y sus metáforas y el sida y sus metáforas, España, Taurus.

Troncoso, Ximena (2003), «El retrato sospechoso: Bello, Lastarria y nuestra ambigua relación con los mapuche», Atenea 488, pp. 153-176.

Fecha de recepción: 15/07/2011

Fecha de aprobación: 12/10/2011
Filantropía, democracia, locura. Diario de una loca de José Victorino Lastarria JUAN D. CID HIDALGO 